\title{
ATAPUERCA Y LOS ORÍGENES DE LA ARQUEOLOGÍA EXPERIMENTAL. INVESTIGACIÓN, EDUCACIÓN Y DIVULGACIÓN DE NUESTRO PASADO.
}

\author{
Atapuerca and the origins of experimental archeology. research, education and \\ dissemination of our past. \\ Rodrigo Alonso-Alcalde ${ }^{12}$ y Marcos Terradillos-Bernal ${ }^{3}$ \\ https://doi.org/10.15366/baexuam2020.14.001
}

\begin{abstract}
Resumen
Este artículo analiza la relación que han tenido los yacimientos de la Sierra de Atapuerca con la Arqueología Experimental. Su presentación se realiza desde tres vertientes. Una vinculada a la aplicación de programas experimentales en la investigación científica desde los primeros trabajos realizados en los yacimientos. Otra segunda relacionada con la implementación de esta disciplina en las universidades situadas en la órbita del Proyecto Atapuerca. En este apartado se realiza un estudio de la implicación de estos centros en la celebración de congresos y jornadas relacionados directamente con la Arqueología Experimental en los últimos años. Finalmente una tercera vertiente que pone de manifiesto la importancia que esta disciplina ha tenido en la divulgación y el desarrollo del turismo cultural vinculado a estos yacimientos.
\end{abstract}

Palabras clave: Historiografía, Atapuerca, educación, turismo cultural.

\begin{abstract}
This article expresses the relationship that the archaeological sites of Sierra de Atapuerca have had with Experimental Archeology. Its study focuses on three aspects. The first one links the application of experimental programs in scientific research since the first works began in the archaeological sites. The second one is related to the implementation of this discipline in the universities related to the Atapuerca Project. In this one, it has been made a study of the involvement of these centers holding congresses and workshops directly related to Experimental Archeology in recent years. Finally, the last aspect shows the importance that this discipline has had in the dissemination and development of cultural tourism linked to these sites.
\end{abstract}

Keywords: Historiography, Atapuerca, education, cultural tourism.

\footnotetext{
${ }^{1}$ Museo de la Evolución Humana (Junta de Castilla y León). Paseo Sierra de Atapuerca n 209002 Burgos ORCID 0000-0002-8853-1150 ralonso@museoevolucionhumana.com

2 Área de Prehistoria de la Universidad de Burgos. Facultad de Humanidades y Comunicación, Paseo de Comendadores, 09001 Burgos.

${ }^{3}$ Facultad de Humanidades y Ciencias Sociales, Universidad Internacional Isabel I de Castilla, C/ Fernán González, n76, 09003 Burgos. ORCID 0000-0003-4710-4627
} 


\section{Introducción}

Aprovechando el trigésimo aniversario de la puesta en marcha del Laboratorio de Arqueología Experimental de la Universidad Autónoma de Madrid (LAEX), es una buena excusa para analizar la relación que la Arqueología Experimental ha tenido con los yacimientos de la Sierra de Atapuerca. Rastreando en las primeras publicaciones científicas sobre estos yacimientos hemos rescatado una de las primeras experimentaciones que se llevaron a cabo en nuestro país en el campo de la Arqueología. Junto a este descubrimiento se ha podido verificar la consolidación que la Arqueología experimental ha alcanzado a lo largo del siglo XXI para el estudio de las sociedades pretéritas. Su flexibilidad metodológica permite generar programas experimentales muy variados y un buen ejemplo lo encontramos en la productividad científica actual vinculada al Proyecto Atapuerca.

El carácter eminentemente práctico y dinámico de esta disciplina la ha convertido en una excelente herramienta en el campo de la docencia Por este motivo muchas universidades a lo largo de este siglo, se han ido dotando de asignaturas relacionadas directamente con la arqueología experimental. Por otra parte, su componente visual y participativo la está convirtiendo en una herramienta esencial para la transmisión del conocimiento arqueológico en un mundo donde el turismo cultural tiene cada vez más seguidores. Atapuerca fue pionera con la puesta en marcha de uno de los primeros Centros de Arqueología Experimental (CAREX) que desde 2001 tiene como esencia dar a conocer los resultados de las excavaciones tomando como base metodológica la experimentación.

Este recorrido historiográfico tiene como principal objetivo constatar un hecho que muchos llevamos defendiendo otros tantos años: la Arqueología experimental es una disciplina esencial para investigar, educar y divulgar sobre nuestro pasado.

\section{Orígenes y actualidad de la experimentación en la Sierra de Atapuerca}

A principio del siglo XX la denominada Cueva de Atapuerca ya era conocida por mucha gente que se aventuraba en su interior para recorrer sus casi $4 \mathrm{~km}$ de galerías. En este sistema kárstico, conocido actualmente como Complejo Cueva Mayor - Cueva del Silo, se localizan toda una serie de yacimientos entre los que podemos destacar: El Portalón, la Sima de los Huesos, la Galería del Sílex, la Cueva del Silo o la Galería de las Estatuas. El estudio de estos lugares está aportando una gran colección de restos que nos permite estudiar la evolución de los grupos humanos desde hace más de 400.000 años hasta la actualidad. Sin embargo, el interés paleolítico por este sitió comenzó muchos años atrás con la visita en 1910 del arqueólogo Jesús Carballo García y del naturalista y futuro arqueólogo Saturio González (Carballo, 1910).

La visita de Carballo y Saturio a Atapuerca se produjo en los años posteriores al reconocimiento internacional de la autenticidad de las pinturas de Altamira (Cartailhac, 1902). El famoso mea culpa d'un sceptique de Cartailhac provocó que durante el primer tercio del siglo pasado gran parte de las investigaciones paleolíticas se enfocaran hacia la 
búsqueda y documentación de sitios con arte rupestre. En este contexto Carballo conoció la cueva de Atapuerca donde señaló:

"Pero lo más saliente en este antro, y que no puede pasar desapercibido, es una pintura, figurando una cabeza de caballo, de ocre rojo, en todo semejante a las de Altamira. ¿Es realmente prehistórica?

Lo ignoro; la respuesta no es de mi competencia, porque nunca me he dado al arte pictórico, ni conozco en España quien haya estudiado a fondo, la pintura prehistórica para decidir, por lo cual debo aguardar a que venga mi amigo Breuil a examinarla" (Carballo, 1910: 472).

El caballo descrito se encuentra en una de las paredes del yacimiento de El Portalón de Cueva Mayor. Sin embargo, lo más significativo del artículo de Carballo radica unas páginas antes donde encontramos evidencias de una de las primeras experimentaciones que sobre arte rupestre se realizaron en nuestro país:

“Cómo es posible que las pinturas se conservasen durante tantos siglos? Esta dificultad no se le ocurrió solamente al Sr. Puig, que también se me ocurrió a mí y a todos los geólogos, que no obstante aprecian la antigüedad de dichas figuras. Mas como los pre historiógrafos, a pesar de reconocer la antigüedad, no daban pruebas positivas y científicas que satisficiesen, yo he querido experimentar antes de inclinarme a opinión alguna.

Así me fui a Altamira, cogí una piedra caliza de la bóveda, la pinté con ocre del que había desenterrado allí mismo y la tuve en un armario (en mi habitación), sin que le diera la luz, pero cuidando de mojarla periódicamente, a fin de conservarla siempre húmeda, corno suelen estar allí. Pasados tres años en estas condiciones, el tono de pintura estaba igual que el primer día, no había bajado nada: la dejó siete meses más en las mismas condiciones, al cabo de los cuales no se alteró lo más mínimo. Por fin la saqué de su prisión, la dejé en el balcón tres días enteres a la luz y a la intemperie, y fueron suficientes para que el tono de la pintura se rebajase de tal modo, que apenas se distinguía; al quinto día la piedra caliza se presentaba blanca, la pintura de ocre había desaparecido. Desde entonces creo que las pinturas de Altamira, en las condiciones que se hallan de obscuridad y humedad, pueden conservarse indefinidamente. Por la misma razón opino que el hombre prehistórico no dejó sus obras artísticas en las cuevas solamente, sino que las dejó indistintamente en las peñas y piedras lisas y en los árboles; más, no reuniendo las condiciones de conservación, han desaparecido. Este es punto importante de tenerse en cuenta, porque hasta ahora nos inclinamos a creer que el arte prehistórico era exclusivamente troglodita.

Como hasta el presente no consta que Martel, ni Rivier, ni Breuil, ni Klaatsch, ni Packard, ni otro alguno de los espeleólogos haya realizado semejantes pruebas, creo tener el derecho de propiedad en decidir de una vez la tan debatida cuestión de la antigüedad de las pinturas, probando con hechos positivos, cual corresponde a las ciencias exactas, que las pinturas de sesquióxido férrico y de bióxido de manganeso, puestas en ciertas 
condiciones, pueden conservarse indefinidamente como las de Altamira y PuenteViesgo" (Carballo, 1910: 470-471).

Del trabajo de Carballo llama la atención principalmente como utiliza la experimentación para intentar verificar la autenticidad cronológica del arte rupestre. Para ello desarrolla un largo programa metodológico, de más de tres años, que le permitió verificar que unas condiciones estables de temperatura, humedad y nula radicación solar podían garantizar la conservación de las pinturas paleolíticas. Así mismo hay que destacar la reflexión en la que señala que las sociedades prehistóricas pudieron realizar este tipo de manifestaciones en otros soportes al aire libre como peñas, piedra o incluso los árboles. Esta visión se enfrentó al "troglodistismo dominante" que construía un discurso de unos grupos humanos paleolíticos eminentemente cavernícolas.

Los resultados de esta experimentación sobre Altamira también los aplicó al estudio que realizó de la cabeza de caballo rojo de El Portalón de la Sierra de Atapuerca donde indicó:

"De todos modos, yo dudo mucho, porque a la luz natural es difícil la conservación de la pintura. Por otra parte, no sería el primer caso que se da, de individuos que cometen la incalificable acción de emborronar la propia honra y reputación, pintando en las cavernas con el exclusivo intento de engañar a los sabios. Tal sucedió aquí el año pasado cuando vino el príncipe de Mónaco. Entonces, alguno que tenía noticia, pintó en una de las varias grutas de Suances (Santander), muchas figuras de animales, reproduciendo posiblemente las clásicas de Altamira.

Afortunadamente, su misma ignorancia le denunció, porque entre otros animales figuró un gallo, especie absolutamente desconocida de los trogloditas magdalenenses y del cual nunca se halló figura alguna, pero ni osamenta siquiera.

Con anticipación yo avisé al abate Breuil, a fin de que entretuviesen de algún modo al príncipe en Altamira, mientras Breuil, el Dr. Obermayer y yo, a toda velocidad en un automóvil, nos llegamos a Suances. Lo primero que les mostré fue el gallo, a cuya vista Breuil indignado escribió debajo de la firma: «esto es falso», haciendo lo mismo con todas las demás que examinó.

Martel, en su Evolution Souterraine, cita casos análogos acaecidos en Francia; que no sucede esto solamente en España, sino también en el extranjero. Así que, sabiendo cuantas trabas la ignorancia humana pone a la ciencia los asuntos arqueológicos, en general fáciles de reproducir, deben ser estudiados con mucha serenidad. No corren, por cierto, tanto peligro los geólogos, porque los estratos arcillosos, por ejemplo, que habiendo sido una solución más o menos concentrada y después hayan precipitado lentamente en el fondo del agua, formando estratos, no podrán ser removidos sin que se conozca a primera vista; y esto asegura la autenticidad de la osamenta y de los objetos hallados en el substratum.

El recuerdo de todas estas circunstancias y el estar la figura citada expuesta a la luz, me hace sospechar de su autenticidad (Carballo, 1910: 472-473). 
Como vemos una experimentación permitió a Carballo plantear la hipótesis que aseveraba que el caballo de la Cueva de Atapuerca parecía corresponderse con una falsificación. Tras la publicación del trabajo de Carballo, otros investigadores como Breuil y Obermaier, acompañados de nuevo de Saturio González, acudieron a la cueva para ver y estudiar dicha pintura (Breuil, 1913: 5-6). A partir de ese momento comenzó un debate sobre la autoría del descubrimiento de la misma, así como por la tipología del animal representado ya que para Breuil la pintura, ahora si auténtica, podía corresponderse también con una cabeza de oso (Breuil, 1920; Breuil, 1921; Carballo, 1921).

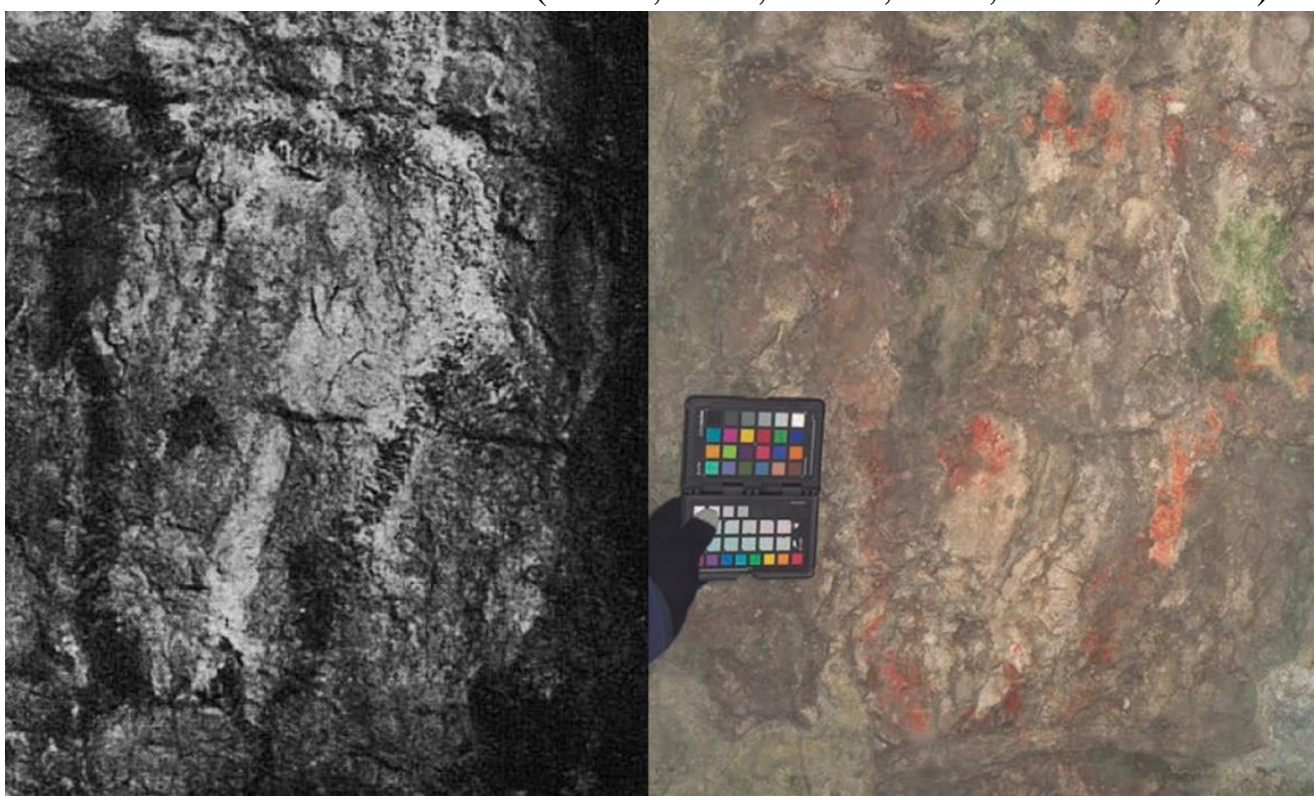

Figura 1. A la izquierda primera fotografía del posible caballo u oso paleolítico realizada por Breuil tras su visita a la cueva en 1912 (Breuil y Obermaier, 1913). A la derecha fotografía tomada durante las últimas investigaciones sobre dicha pintura (Fernández Moreno et al, 2019)

Años más tarde el geólogo Jesús Royo y Gómez en su publicación vinculada a la excursión A6 del XIV Congreso Geológico Internacional, celebrado en Madrid 1926, y que tenía como objetivo conocer el Terciario continental de Burgos, negó la autenticidad paleolítica de dicha pintura en los siguientes términos:

"Esta cueva de Atapuerca es de grandes dimensiones y bastante notable, por sus formaciones estalactíticas y estalagmíticas, pues aunque se ha señalado en ella la existencia de pinturas y grabados prehistóricos, en realidad se trata de figuras modernas o meramente casuales, y así en el lugar en que se había indicado una cabeza de oso en rojo, se ve una cabeza muy tosca de caballo y completamente actual" (Royo y Gomez, 1926: 64).

La opinión de Royo y la hipótesis de Carballó cayeron en saco roto, prevaleciendo la autenticidad de la misma que defendió Breuil. La autoridad mundial que representaba Breuil motivó que ningún otro investigador se planteara dudas sobre la autenticidad de dicha pintura lo largo del siglo XX. De esta manera, la cabeza pintada en la Cueva de Atapuerca pasó a formar parte de todos los manuales que recogían los yacimientos con arte rupestre del Paleolítico superior en la Península Ibérica (Ortega y Martín, 2012: 217).

Esta situación cambió con la llegada del siglo XXI, cuando un trabajo encabezado por Marcos García y Ana Isabel Ortega volvió a cuestionar la autenticidad paleolítica de la 
mencionada representación en base a un análisis historiográfico, contextual y gráfico. Concluyendo que la figura se corresponde con un équido pintado a principios del siglo XX (García et al. 2001: 153, 157,166). Lejos de quedar zanjado el tema un reciente trabajo basado la aplicación de un estudio fotográfico combinado con el análisis de muestras de pigmentos mediante microscopía Raman ha abierto nuevas posibilidades de estudio (Fernández Moreno et al., 2019). La microespectroscopía detectó micropartículas de hematites y de carbón amorfo, lo que posibilitó la datación por radiocarbono de una muestra (AMS ${ }^{14} \mathrm{C}$.) que dio como resultado que la pintura se realizó en un momento indeterminado de la Edad Media o Moderna. Sin embargo los autores exponen la posibilidad de que el pigmento pueda estar alterado o contaminado por la vegetación circundante o por la manipulación de la pintura en los procesos de estudio y calco directo.

Independientemente del amplio recorrido historiográfico de la pintura localizada en El Portalón de Cueva Mayor, la verdadera singularidad radica en que la experimentación realizada por Carballo y que aplicó al estudio de dicha pintura marcó el inicio de la relación entre la experimentación y las investigaciones en los yacimientos de la Sierra de Atapuerca. Si bien es cierto, que hubo que esperar hasta el cambio de siglo para que el desarrollo sistemático de programas experimentales formaran para de las metodologías de trabajo desarrolladas en el marco del proyecto de investigación.

Hoy en día la Arqueología Experimental forma parte de la realidad cotidiana en las investigaciones realizadas sobre los materiales y yacimientos de la Sierra de Atapuerca y abarcan todo tipo de disciplina y estudios como por ejemplo: traceología (Pedergnana y Ollé, 2019; Ollé y Verges, 2014); materias primas (Terradillos-Bernal y Rodríguez Álvarez, 2017); tafonomía (Arilla et al, 2020; Domínguez-Rodrigo et al, 2017); canibalismo (Marginedas et al, 2020); Paleoneurobiología (Fedato et al , 2019); Música (Cuartero et al, 2018); Lateralidad (Bargalló et al, 2018); Biomecánica (Patiño et al, 2017); Comunicación y aprendizaje (Lombao et al, 2017); Pirotecnología (Carrancho et al, 2014); didáctica (López-Castilla et al, 2019) o Bioenergía (Mateos et al, 2019).

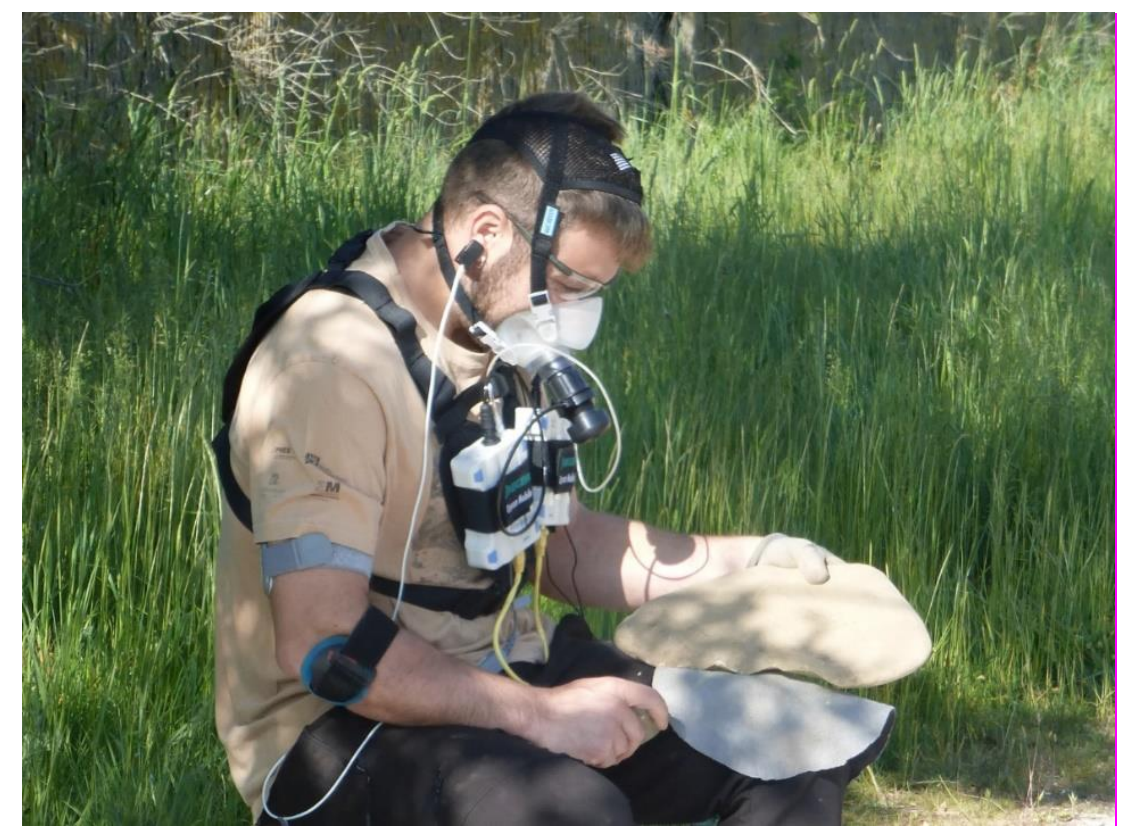

Figura 2. Programa experimental para calcular el gasto energético durante los procesos de talla (Mateo et al, 2019). 


\section{La Arqueología Experimental como herramienta educativa}

La aplicación de la Arqueología Experimental al campo de la educación es algo relativamente reciente. No es así en otros campos como la museología, donde la Arqueología Experimental comenzó a utilizarse con la aparición de los primeros Parques Arqueológicos en los países del norte de Europa durante la década de los 70. Su aplicación dentro del ámbito académico español está vinculada con la Universidad Autónoma de Madrid (UAM) en la década de los 90 del siglo pasado. En este marco la UAM incorporó a sus planes de estudio dicha disciplina a la vez que ponía en marcha el primer Laboratorio de Arqueología Experimental Universitario de nuestro país (Palomo et al, 2018).

Siguiendo esta estela desde Área de Prehistoria de la Universidad de Burgos (UBU) ofertó para el curso académico 1999-2000 una asignatura, denominada "Tecnología Prehistórica". Esta universidad, relacionada directamente con el Proyecto Atapuerca, planteó esta asignatura con una doble finalidad: generar referentes de las principales actividades desarrolladas a lo largo de la Prehistoria y presentar las técnicas, tecnologías y modos de vida del pasado desde una perspectiva más visual, interactiva y con una programación eminentemente empírica.

Esta asignatura se planteó para un grupo máximo de 15 alumnos y en ella se presentaban los principales avances tecnológicos producidos durante la Prehistoria de una manera eminentemente práctica. El objetivo se centró en que el alumno desarrollase varios programas experimentales relacionados con estos procesos tecnológicos para que comprenda con una mayor claridad cómo el ser humano en la Prehistoria planificó sus acciones, cuáles eran sus objetivos, las diferentes técnicas, materias primas, productos y subproductos, así como su posible funcionalidad. Tras veinte años de impartición de esta asignatura se ha podido concluir que la Arqueología Experimental es una disciplina que despierta un gran interés y curiosidad en los alumnos, que les proporciona conocimientos imposibles de adquirir desde otras vías de estudio y que éstos se transmiten de una forma amena.

Junto al desarrollo de esta asignatura, el Área de Prehistoria de esta universidad organizó otra serie de acciones educativas que tenían en la Arqueología Experimental su metodología de trabajo. De esta forma se llevaron a cabo las jornadas "Arqueología Viva: Jornadas de recreación de actividades prehistóricas" el 24 y 25 de abril de 2002 y "La experiencia como forma de conocimiento del pasado" en los días 11 y 12 de abril de 2005. En ambas participaron como ponentes destacados investigadores en el campo de la experimentación en Arqueología. Del mismo modo se desarrollaron artículos sobre Arqueología Experimental en la publicación trimestral Diario de los Yacimientos de la Sierra de Atapuerca desde 2004 hasta 2010, a la vez que se generaron productos editoriales como el libro Cómo sobrevivir con dos piedras y un cerebro. Manual práctico de Arqueología Experimental (Díez y Nastri, 2011).

Durante el siglo XXI otras universidades y centros de investigación vinculados al Proyecto Atapuerca comenzaron a integrar en sus planes docentes asignaturas y programas vinculados con la Arqueología Experimental, tal es el caso de la Universitat 
Rovira i Virgili (URV) y el Institut Català de Paleocologia Humana i Evolució Social (IPHES) ambos situados en la ciudad de Tarragona.

El carácter eminentemente empírico de la Arqueología Experimental la convierte en una buena herramienta para familiarizar al alumnado con el método científico hipotéticodeductivo. Por este motivo cada vez es más frecuente que en los trabajos de fin de grado y de fin de master vinculados a la Arqueología las experiencias y experimentaciones tengan un mayor protagonismo.

En el campo de la educación e investigación un hito fundamental en el desarrollo de la Arqueología Experimental en España fue la puesta en marcha en 2005 de la Asociación Española de Arqueología Experimental (Experimenta). El desarrollo de esta asociación ha estado vinculado a la organización de los Congresos Internacionales de Arqueología Experimental. Hasta la fecha se han celebrado cinco reuniones que han generado una producción científica de 258 artículos.

La vinculación de miembros del Proyecto Atapuerca al desarrollo y funcionamiento de Experimenta ha estado presente desde la puesta en marcha de la asociación. Del mismo modo su participación ha sido clave en la organización de los congresos celebrados en Burgos en 2014 y Tarragona en 2018 respectivamente (Alonso et all, 2017; Cáceres et all, 2018). El Proyecto Atapuerca ha contribuido con 29 artículos en el desarrollo de los cinco congresos lo que supone un $11,24 \%$ sobre la totalidad de los trabajos.

\begin{tabular}{|c|c|l|}
\hline AÑ & CIUDAD & PUBLICACIÓN \\
\hline 2005 & Santander & $\begin{array}{l}\text { Ramos, M.L., González, J.E., Baena, J. (Eds.) 2007. Arqueología experimental en la } \\
\text { Península Ibérica: Investigación, didáctica y patrimonio. Asociación Española de } \\
\text { Arqueología Experimental. Santander. Pp. 343. }\end{array}$ \\
\hline 2008 & Ronda & $\begin{array}{l}\text { Morgado, A., Baena, J., García, D. (Eds.) 2011. La investigación experimental } \\
\text { aplicada a la Arqueología. Universidad de Granada, Universidad Autónoma de } \\
\text { Madrid y Experimenta: Asociación Española de Arqueología Experimental. Ronda. } \\
\text { Pp. 509. }\end{array}$ \\
\hline 2011 & Banyoles & $\begin{array}{l}\text { Palomo, A., Piqué, R., Terradas, X. (Eds.) 2013. Experimentación en Arqueología: } \\
\text { Estudio y difusión del pasado. Sèrie Monogràfica; 25, Museu d'Arqueologia de } \\
\text { Catalunya-Girona.2 vol. Girona. Pp.524. }\end{array}$ \\
\hline Burgos & $\begin{array}{l}\text { Alonso, R., Baena, J., Canales, D. (Eds.) 2017. Playing with the time. Experimental } \\
\text { archaeology and the study of the past. Servicio de Publicaciones de la Universidad } \\
\text { Autónoma de Madrid. Madrid. Pp. 360. }\end{array}$ \\
\hline
\end{tabular}

Figura 3. Evolución del número de artículos publicados con motivos de los Congresos Internacionales de Arqueología Experimental y contribución a los mismos de miembros del Equipo de Investigación de Atapuerca (EIA). 


\section{La experimentación una herramienta divulgativa en la Sierra de Atapuerca}

La Arqueología Experimental se ha convertido en los últimos años en una importante herramienta didáctica en los centros de interpretación de yacimientos arqueológicos, museos y aulas universitarias por su gran capacidad para transmitir conocimientos. En nuestro país todo este tipo de experiencias aplicadas al campo del turismo cultural comenzaron a desarrollarse desde finales de los 90 y se han ido generalizando en lo que llevamos de siglo XXI. La aplicación de estas herramientas permite acercar al gran público de una manera amena y divertida como se produjeron los principales avances tecnológicos acontecidos durante la Prehistoria (diferentes formas de tallar la piedra, cómo hacer herramientas en hueso, de qué manera se pude fabricar una cuerda, etc.) (Maqueda et al, 2017).

El Equipo de Investigación de Atapuerca (EIA) siempre ha tenido en cuenta la importancia de la experimentación a la hora de transmitir el conocimiento científico a la ciudadanía. Así tenemos como en 1995 durante la celebración de las primeras jornadas de puertas abiertas a los yacimientos de la Sierra de Atapuerca, estas se complementaron con demostraciones de talla lítica Esta actividad permitió a los visitantes acercarse a la realidad arqueológica de una forma totalmente diferente a las fórmulas desarrolladas hasta el momento, pudiendo incluso llevar a cabo experiencias personales de talla, en las cuales los visitantes pudieron intentar replicar herramientas de piedra similares a las documentadas en los yacimientos.

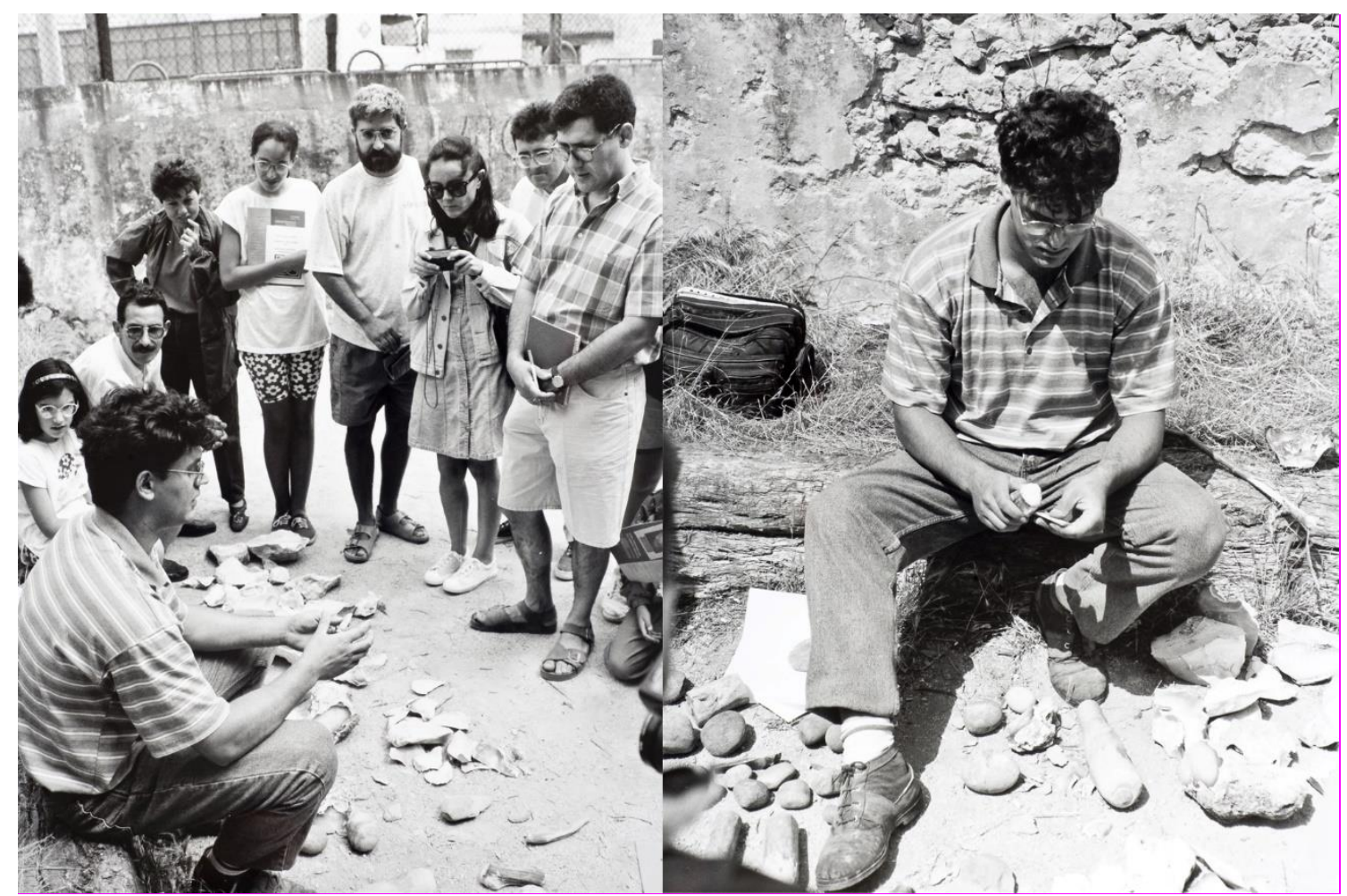

Figura 4. Demostraciones de talla lítica durante la primera jornada de puertas abiertas realizadas en los yacimientos de la Sierra de Atapuerca en 1995 (Alfonso Alonso/Diario de Burgos). 
A partir de 1998 comenzaron a sistematizarse las visitas a la Sierra de Atapuerca. El auge que a finales de los 90 en Europa estaba adquiriendo el denominado Turismo Cultural motivó el diseño de nuevas infraestructuras que aunaran la difusión y la divulgación. El desarrollo que en esos momentos estaban teniendo en España los Parques Arqueológicos como nuevas instalaciones divulgativas también se materializó en la Sierra de Atapuerca en el cambio de siglo. La Junta de Castilla y León, con el asesoramiento del EIA, decidió apostar por esta nueva fórmula de dar a conocer la realidad arqueopaleontológica de la Sierra. Así, en el verano de 2001 se inauguró en la localidad de Atapuerca, el Parque Arqueológico de Atapuerca. Este recurso puede definirse como un recinto visitable estructurado de tal manera, que el visitante pueda acercarse de forma dinámica y participativa a la arqueología de la Sierra. El Parque está articulado en tres grandes áreas coincidentes con los tres periodos en los que se ha dividido tradicionalmente la Prehistoria (Paleolítico, Neolítico y Edad de los Metales). Este tipo de estructuración permite generar en el visitante una lectura cronológica de la Prehistoria tomando como base los resultados de las investigaciones realizadas en la Sierra de Atapuerca (Alonso, 2011: 127).

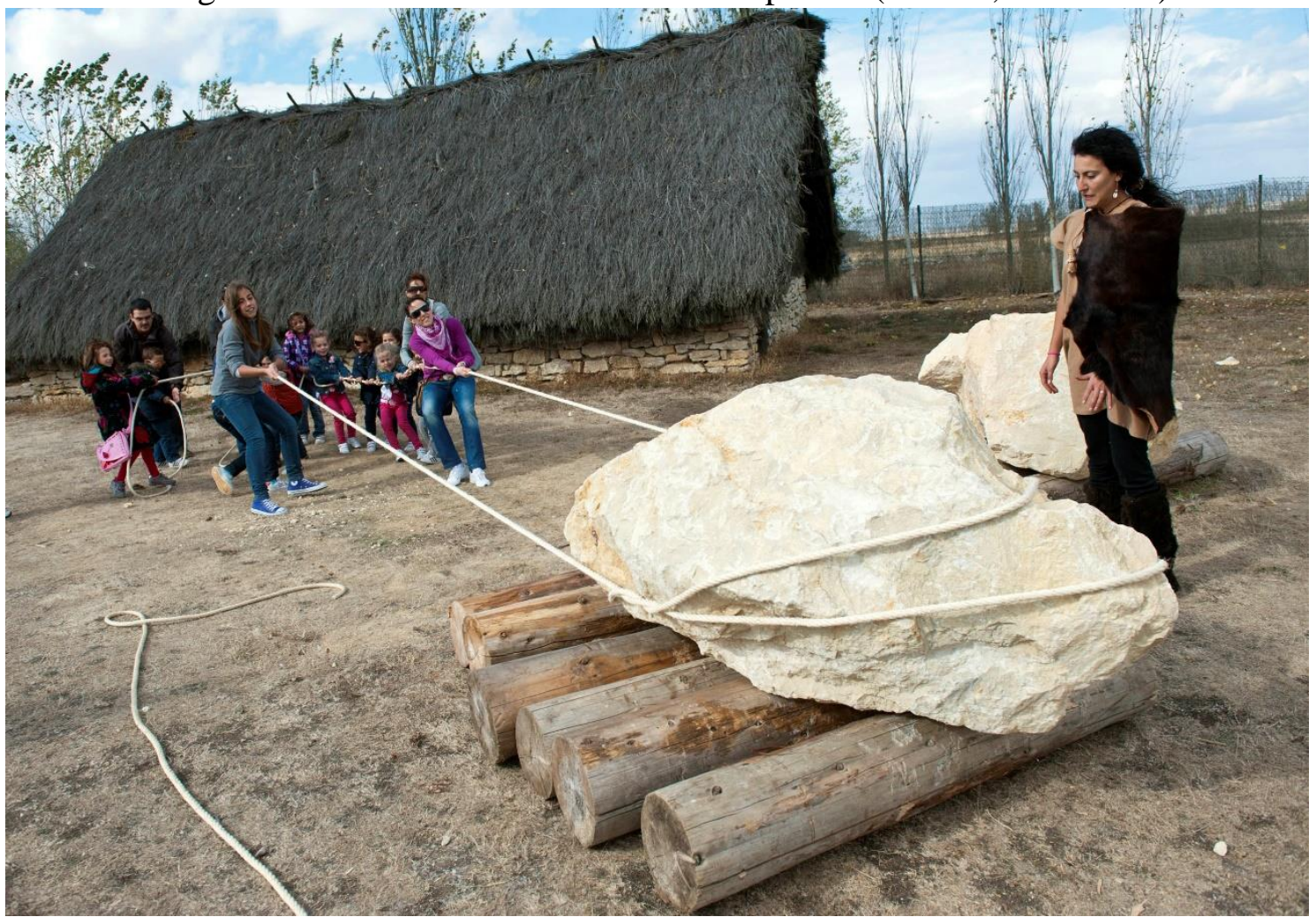

Figura 5. La primera fase constructiva del Centro de Arqueología Experimental de Atapuerca (CAREX) se inauguró en 2001, convirtiéndose en uno de los primeros parques arqueológicos de la Península Ibérica (Agencia ICAL).

En 2015 se reestructuro el complejo generando un nuevo recorrido complementario donde el visitante tiene la oportunidad de forma autónoma de aprender alguno de los procesos tecnológicos acontecidos durante la prehistoria (obtener fuego por percusión, utilización de un taladro de bailarina, aserrado de madera, curtido de pieles etc.). En su reforma se contó con el asesoramiento y participación del LAEX-UAM. La nueva infraestructura resultante se conoce como Centro de Arqueología Experimental de Atapuerca (CAREX) y en ella se desarrollan tanto actividades educativas como una programación cultural abierta para todos los habitantes que viven en la ladera norte de la Sierra de Atapuerca. 
El CAREX se ha convertido en un recurso clave en la visita a los yacimientos de la Sierra de Atapuerca. Para articular la gestión de todas las infraestructuras que se habían ido generando alrededor del Proyecto Atapuerca la Junta de Castilla y León creó el Sistema Atapuerca Cultura de la Evolución (SACE). Esta nueva figura es un "sistema integrado de gestión y colaboración entre diferentes equipamientos, centros, servicios y departamentos, con los objetivos de valorizar, explotar y enriquecer los recursos culturales y científicos asociados a los yacimientos arqueo-paleontológicos de la Sierra de Atapuerca" (BOCYL 39/2009). Anualmente, y sin tener en cuenta la programación cultural, el SACE es visitando por una media de 300.000 visitas que se reparten de la siguiente manera: Museo de la Evolución Humana de Burgos 150.000 visitas, los Yacimientos de la Sierra de Atapuerca 80.000 visitas y el CAREX 70.000 visitas.

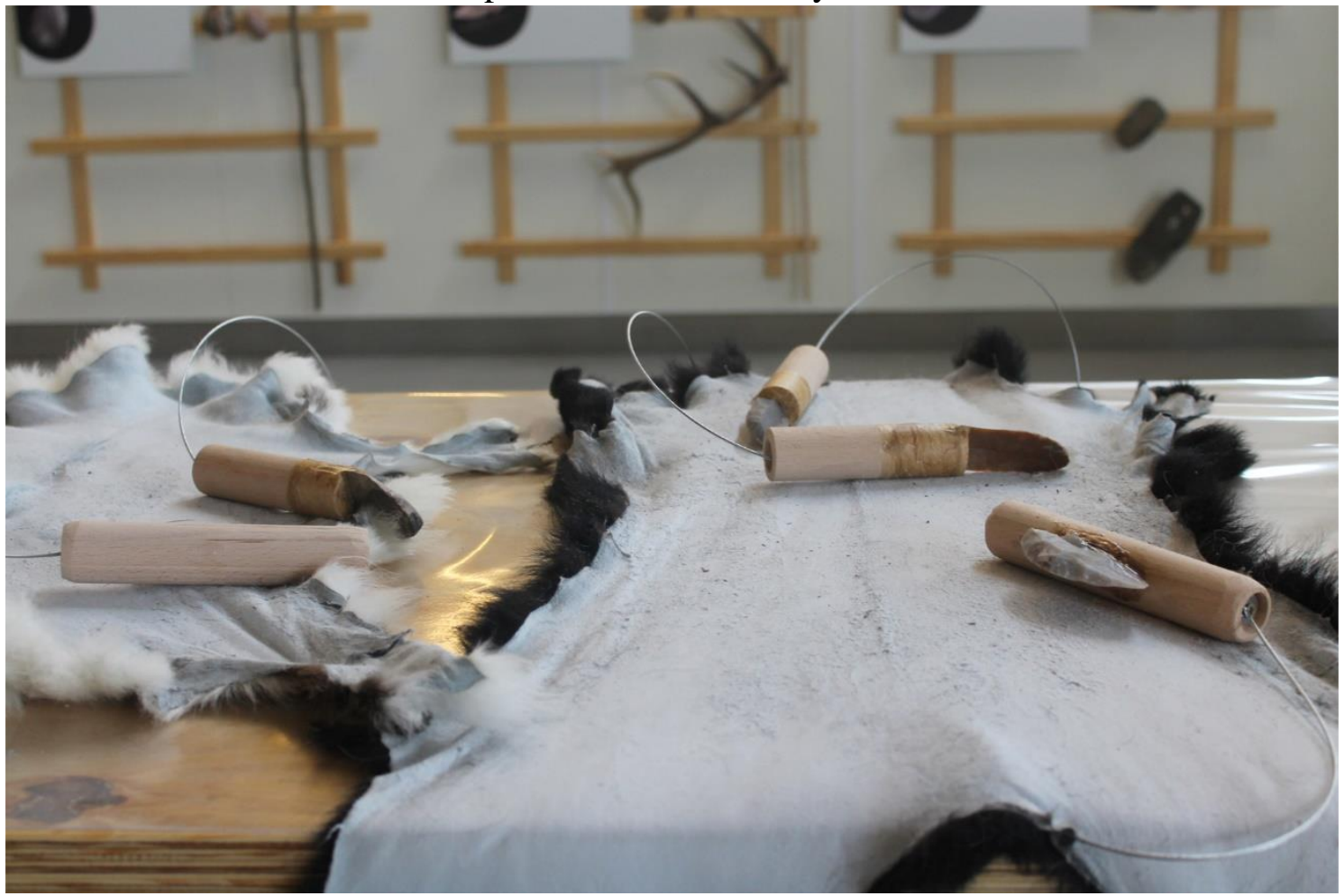

Figura 6. En 2015 se reestructuró el Centro de Arqueología Experimental de Atapuerca (CAREX) con el desarrollo de un nuevo recorrido donde el visitante tiene la posibilidad de realizar de forma autónoma algunas experiencias vinculadas a procesos tecnológicos prehistóricos.

\section{Epílogo}

No podemos finalizar este trabajo sin perder la perspectiva del confinamiento que nos está tocando vivir por la pandemia del coranovirus COVID-19 iniciada en Wuhan (China) a finales de 2019. La extensión de este virus ha provocado una situación desconocida hasta el momento como es el confinamiento en nuestras casas de la mitad de la población mundial o lo que es lo mismo casi 4.000 millones de personas. Esta situación ha provocado que muchos arqueólogos nos hayamos refugiado en la experimentación como herramienta de distracción para soportar mejor nuestro confinamiento. Sin embargo no olvidamos que la Arqueología Experimental es mucho más que un juego (Baena et al, 2019; Baena, 1997), es una excelente herramienta que supera con creces su factor lúdico para convertirse en una disciplina que mediante la experimentación, recogida de datos y 
verificación de hipótesis nos permite conocer empíricamente como realmente se desarrollaron estos procesos tecnológicos en el pasado.

\section{Agradecimientos:}

Este trabajo se ha realizado en el marco de los proyectos: The Pleistocene and Holocene of the Sierra de Atapuerca. Hominin settlement patterns in Europe, Chronological, Spatial and Environmental frame, and Cognition and Technology. MINECO/FEDER, PGC2018093925-B-C31. Eco-Social behaviour of the Sierra de Atapuerca hominines during Quaternary and Holocene V.: MICINN-FEDER, PGC2018-093925-B-C32.

\section{Bibliografía}

ALONSO, R., CANALES D., BAENA, J., (EDS). (2017): Playing with the time. Experimental archeology and the study of the past, Servicio de Publicaciones de la Universidad Autónoma de Madrid.

ALONSO, R., (2011): La Sierra de Atapuerca, una forma activa de acercarse al pasado. En Díez, J.C., Nastri, J. (Eds.) Cómo sobrevivir con dos piedras y un cerebro. Manual práctico de Arqueología Experimental, pp. 125-129. Diario de los Yacimientos de la Sierra de Atapuerca, Burgos

ARILLA, M., ROSELL, J., y BLASCO, R. (2020): “A neo-taphonomic approach to human campsites modified by carnivores". Scientific Reports, 10(1): 6659. doi: 10.1038/s41598-020-63431-8.

BAENA PREYSLER, J. (1997): "Arqueología experimental, algo más que un juego". Boletín de Arqueología Experimental, 1: 2-5.

JAVIER BAENA PREYSLER, J., TORRES NAVAS, C. y PALOMO, A. (2019): “Seguimos jugando cuando hablamos de Arqueología Experimental?”. Boletín de Arqueología Experimental, 13 (2018-2019): 1-8.

BARGAlló, A., MOSQUERA, M., y LORENZO, C. (2018): "Identifying handedness at knapping; an analysis of the scatter pattern of lithic remains". Archaeological and Anthropological Sciences, 10 (3): 587-598.

BREUIL, H. (1920): "Miscellanea d'art rupestre (1)." Boletín de la Real Sociedad española de Historia Natural, 20: 322-333.

BREUIL, H. (1921): "Rectificación que emite el abate Henri Breuil, con motivo de una nota del Sr. Carballo." Boletín de la Real Sociedad española de Historia Natural, 21: 269-271.

BREUIL, H. y OBERMAIER, H. (1913): "Travaix exécutés en 1912." L'Anthropologie, 24 (1): 1-16. 
CÁCERES, I. EXPÓSITO, I. FONTANALS, M., CHACÓN, M.G. y VERGÈS, J.M., (Eds.). (2018): Experimental Archaeology: From research to society. Butlletí Arqueològic, 40. Reial Societat Arqueològica Tarraconense, Tarragona.

CARBALlO, J. (1910): "De espeleología." Boletín de la Real Sociedad española de Historia Natural, 10: 468-481.

CARBAllo, J. (1921): "Las cuevas de Atapuerca y San García (Burgos)". Boletín de la Real Sociedad española de Historia Natural, 21: 138-141.

CARRANCHO, A., MORALES, J., GOGUICHAICHVILI, A., ALONSO, R., y TERRADILLOS, M. (2014): "Thermomagnetic monitoring of lithic clasts burned under controlled temperature and field conditions. Implications for archaeomagnetism". Geofísica Internacional, 53 (4): 473-490.

CARTAILHAC, E. (1902): "La grotte d'Altamira, Espagne. Mea culpa d'un sceptique". L'Anthropologie, 13: 348-354.

CUARTERO MONTEAGUDO, F., TERRADILLOS BERNAL, M., CANALES CAMARERO, D., ALONSO ALCALDE, R., y ALCARAZ-CASTAÑO, M., (2018): Una aproximación a la problemática de los zumbadores magdalenienses a partir de la experimentación: influencia de las proporciones métricas en la sonoridad. En I. Cáceres, I. Expósito, M. Fontanals, M. G. Chacón, \& J. M. Vergès (Eds.), Experimental Archaeology: From research to society. Butlletí Arqueològic , 40, pp. 219-224), Reial Societat Arqueològica Tarraconense, Tarragona.

DÍEZ, J.C., NASTRI, J., (Eds.) (2011): Cómo sobrevivir con dos piedras y un cerebro. Manual práctico de Arqueología Experimental, Diario de los Yacimientos de la Sierra de Atapuerca, Burgos.

DOMÍNGUEZ-RODRIGO, M., SALADIÉ, P., CÁCERES, I., HUGUET, R., YRAVEDRA, J., RODRÍGUEZ-HIDALGO, A., MARTÍN, P., PINEDA, A., MARÍN, J., GENÉ, C., ARAMENDI, J., COBO-SÁNCHEZ, L. (2017): “Use and abuse of cut mark analyses: The Rorschach effect". Journal of Archaeological Science, 86: 14-23.

FEDATO, A., SILVA-GAGO, M., TERRADILlOS-BERNAL, M., ALONSOALCALDE, R., MARTÍN-GUERRA, E., y BRUNER, E. (2019): "Electrodermal activity during Lower Paleolithic stone tool handling". American Journal of Human Biology, 31: e23279. https://doi.org/10.1002/ajhb.23279

FERNANDEZ MORENO, J.J., GARCÍA ALONSO, B., PAREDES ROIBÁS, D., ROWE, M.W., HERNANZ, A., y ARSUAGA, J.L. (2019): “A vueltas con la cronología del prótomo pintado en El Portalón de Cueva Mayor” (Ibeas de Juarros, Burgos). Munibe Antropologia-Arkeologia, 70: 73-92. 
GARCÍA, M., ORTEGA, A.I., MARTíN, M.A., HORTOLÁ, P., ZULUAGA, M.C., 2001: “Arte rupestre de estilo Paleolítico del Portalón de Cueva Mayor de la Sierra de Atapuerca (Ibeas de Juarros, Burgos): ¿cronología paleolítica o contemporánea?". Trabajos de Prehistoria, 58: 153-169.

LOMBAO, D., GUARDIOLA, M., y MOSQUERA, M. (2017): "Teaching to make stone tools: new experimental evidence supporting a technological hypothesis for the origins of language". Scientific Reports, 7: 14394. https://doi.org/10.1038/s41598-017-14322-y

LÓPEZ-CASTILLA, M. P., TERRADILLOS-BERNAL, M., y ALONSO ALCALDE, R. (2019): "Experimental archaeology and historical empathy: key tools for learning about our origins". Cultura y educación, 31 (1): 170-187.

MAQUEDA GARCÍA-MORALES, R., y LUQUE CORTINA, M. (2017): "Experimental and experiential archaeology in Spain: Atapuerca (Burgos) and Arqueopinto (Madrid)". En R. Alonso, D. Canales, \& J. Baena (Eds.), Playing with the time. Experimental archeology and the study of the past, pp. 349-354. Madrid: Servicio de Publicaciones de la UAM.

MARGINEDAS, F., RODRÍGUEZ-HIDALGO, A., SOTO, M., BELLO, S. M., CÁCERES, I., HUGUET, R., y SALADIÉ, P. (2020): "Making skull cups: Butchering traces on cannibalised human skulls from five European archaeological sites". Journal of Archaeological Science, 114: 105076. https://doi.org/10.1016/j.jas.2020.105076.

MATEOS, A., TERRADILLOS-BERNAL, M., y RODRÍGUEZ, J. (2019): “Energy Cost of Stone Knapping”. Journal of Archaeological Method and Theory, 26 (2): 561580.

OLLÉ, A., y VERGÈS, J. M. (2014): "The use of sequential experiments and SEM in documenting stone tool microwear". Journal of Archaeological Science, 48: 6072.

PALOMO, A., AGUIRRE, M., y BAENA, J. (2018): "La talla lítica experimental en España”. En I. Cáceres, I. Expósito, M. Fontanals, M. G. Chacón, \& J. M. Vergès (Eds.), Experimental Archaeology: From research to society. Butlletí Arqueològic , 40, pp. 195-200. Tarragona: Reial Societat Arqueològica Tarraconense.

PATIÑO, F. Y., LUQUE, M., TERRADILLOS-BERNAL, M., y MARTÍN-LOECHES, M. (2017): "Biomechanics of microliths manufacture: a preliminary approach to Neanderthal's motor constrains in the frame of embodied cognition". Journal of Anthropological Sciences, 95: 203-217.

PEDERGNANA, A., OLLÉ, A. (2019): "Use-wear analysis of the late Middle Pleistocene quartzite assemblage from the Gran Dolina site, TD10.1 subunit 
Rodrigo Alonso-Alcalde y Marcos Terradillos-Bernal. Atapuerca y los orígenes de la arqueología experimental. Investigación, educación y divulgación de nuestro pasado

(Sierra de Atapuerca, Spain)". Quaternary International. https://doi.org/10.1016/j.quaint.2019.11.015

ROYO GÓMEZ, J., (1926): Terciario continental de Burgos. Excursión A6. XIV Congreso Geológico Internacional Madrid 1926, Instituto Geológico de España, Madrid.

TERRADILLOS-BERNAL， M., y RODRÍGUEZ-ÁLVAREZ，X. P. (2017): “The influence of raw material quality on the characteristics of the lithic tool edges from the Atapuerca sites (Burgos, Spain)". Quaternary International, 433(A): 211-223. 